\title{
MOBILE APPLICATIONS FOR BUSINESS
}

\author{
N. Angelova* \\ Faculty of Economics, Trakia University, Stara Zagora, Bulgaria
}

\begin{abstract}
The development of mobile technologies and Internet connectivity has a beneficial effect on the creation of diverse mobile applications related to different spheres of life. The time when people used their phones only for making phone calls passed away and nowadays every one of us has a small computer in his pocket that provides unlimited opportunities for training, business and entertainment. The purpose of this work is to present some of the most commonly used mobile applications that are designed to facilitate business communication, financial operations, staff and customer management. The main mobile technologies, operating systems and features of mobile applications are described. A survey about the usage of mobile technologies and applications is conducted and the results are presented.
\end{abstract}

Key words: mobile technologies, mobile communications, Android, iOS, application stores, survey

\section{INTRODUCTION}

We live in a world full of devices from a new generation and technological solutions that have the main task to facilitate our daily lives and routine and this also reflects on the way of thinking and working. It was not so long ago when mobile phones were devices that allowed us to make phone calls and to connect with others when we were out of our homes and just walking or travelling. We are witnesses of an extremely rapid development of mobile technologies over the last decades, and mobile phones have become more accessible to the average consumer, including more services for messaging, listening to music, playing games, taking pictures and all kind of entertainment (1).

The development of the Internet and the transition from $1 \mathrm{G}$ to $5 \mathrm{G}$ wireless mobile networks also required the transformation from mobile phones to smartphones. Now every company working in the area of mobile technologies and producing smartphones is looking to meet the endless demands of consumers whose lives are almost entirely

\footnotetext{
*Correspondence to: Nadezhda Angelova, Faculty of Economics, Trakia University - Stara Zagora,Bulgaria,nadja@uni-sz.bg
}

connected with these devices. In modern life each of us carries in his pocket or a purse this small device having the power and functionality of a computer. It has the potential to be our personal assistant, reminding us of appointments and tasks, creating different documents and sharing them with colleagues, managing the appliances in our home and many other opportunities that we cannot even imagine.

This work aims to make an overview of some mobile applications that can be used for business purposes and presents the results of a survey about the usage of such applications.

\section{MOBILE TECHNOLOGIES}

There is no unambiguous definition of mobile technology, but according to (2) it can be described as a part of technology that involves mobility, uses communication infrastructures, protocols, and portable devices used for cellular communication and allows users to perform various tasks flexibly in terms of time and place. As can be seen these definitions define mobile technologies from a different perspective - the hardware features of different devices and the software solutions that determine technology as mobile. Some of the technologies used in modern smartphones 
include the use of high-speed internet, biometrics data of fingerprint and face scanning for greater protection and security, NFC (Near Field Communication) payments, smart cameras to track and analyze objects, flexible electronics applicable not only to curved screens, but to the devices as a whole.

\subsection{MOBILE OPERATING SYSTEMS}

A major part of mobile technologies are also related to the creation and development of mobile operating systems (OS). By definition, this is an OS that is designed to go on mobile devices like tablets, phones, PDAs and other portable devices. Its main features are hardware management and various additional applications that can be installed. This includes multimedia features, Internet connectivity, keyboard, touch screen, navigation, camera and many more (3).
Several mobile operating systems are mainly used on the market today, such as Android, iPhone OS / iOS, Samsung, BlackBerry, Windows. Some of them are not interchangeable among the devices. This means that Apple iOS can't be run on Android phone and vice versa.

According to market surveys worldwide, the main leader of mobile operating systems is Android OS that is installed on most smartphones, while iOS market share is concentrated in countries that mainly produce and sell devices that support this OS. The market share 2019 of the most popular mobile OS for some technologically developed countries like US, UK, Japan, China, Germany and Russia compared with Bulgaria is presented in Table 1 (4).

Table 1. Mobile Operating System Market Share 2019

\begin{tabular}{|l|l|l|l|l|l|l|l|}
\hline \multirow{2}{*}{ Mobile OS/ } & \multicolumn{7}{|c|}{ Country } \\
\cline { 2 - 8 } & US & \multicolumn{1}{|c|}{ UK } & China & Japan & Germany & Russia & Bulgaria \\
\hline iOS & $55,07 \%$ & $49,81 \%$ & $24,1 \%$ & $71,9 \%$ & $28,38 \%$ & $26,6 \%$ & $\mathbf{1 3 , 9 \%}$ \\
\hline Android & $44,61 \%$ & $49,42 \%$ & $74,6 \%$ & $27,81 \%$ & $70,67 \%$ & $72,32 \%$ & $\mathbf{8 5 , 2 2 \%}$ \\
\hline Windows & $0,1 \%$ & $0,45 \%$ & $0,05 \%$ & $0,03 \%$ & $0,38 \%$ & $0,56 \%$ & $0,45 \%$ \\
\hline Samsung & $0,07 \%$ & $0,18 \%$ & $0,01 \%$ & & $0,43 \%$ & $0,1 \%$ & $0,27 \%$ \\
\hline BlackBerry & $0,05 \%$ & $0,05 \%$ & $0,02 \%$ & $0,01 \%$ & $0,03 \%$ & & \\
\hline Unknown & $0,03 \%$ & $0,02 \%$ & $0,81 \%$ & $0,06 \%$ & $0,03 \%$ & & $0,02 \%$ \\
\hline Playstation & $0,01 \%$ & $0,01 \%$ & & $0,01 \%$ & & & \\
\hline Linux & $0,01 \%$ & & $0,39 \%$ & & $0,02 \%$ & & $0,03 \%$ \\
\hline Series 40 & & & & & $0,03 \%$ & $0,08 \%$ & $0,03 \%$ \\
\hline Nokia Unknown & & $0,02 \%$ & & & & $0,06 \%$ & $0,05 \%$ \\
\hline Other & $0,04 \%$ & $0,04 \%$ & $0,01 \%$ & $0,02 \%$ & $0,05 \%$ & $0,11 \%$ & $0,03 \%$ \\
\hline
\end{tabular}

There are some open source mobile operating systems that are alternative to Android, such as KaiOS, Tizen, PureOS/Librem, Ubuntu touch which are based on Linux, Ubuntu or other open source projects. As an open source OS they are designed to run on any mobile device, but for some of them manufacturers produced specific smartphones. The main idea is developing a mobile operating system free from Google that replaces Google services with its own and promises to not track users or sell their data to advertisers like Google (5).

\subsection{MOBILE COMMUNICATIONS}

The development of mobile technologies, operating systems and devices is related and follows the development of mobile communications. They allow users to communicate with others located in different places without using any physical connections like cables and wires (6).
Mobile communications are conventionally divided into generations marked with a digit and "G" (G stands for generation) - 1G, 2G, $3 \mathrm{G}, 4 \mathrm{G}, 5 \mathrm{G}$. This division is conditional, because most generations unite several standards of data transfer. Infrastructure of mobile operators consists of creating a cellular network of partially overlapping radio-range zones called cells. This is the main reason, why mobile technologies are often called cellular.

The first generation 1G mobile communications uses an analogue voice-only connection. This generation is connected with the first mobile phones.

The second generation 2G standard is Global Service for Mobile Communications (GSM), though not the only one. The start of $2 \mathrm{G}$ is in 1991 and the data transfer rate is $9.6 \mathrm{kbit} / \mathrm{s}$. Eight years later, the GPRS standard (also known as Intermediate Generation - 2.5G), 
which allows the use of high-speed mobile Internet as well as EDGE for mobile TV, is also integrated into the GSM standard.

The third generation 3G mobile communications started in 2002. It includes 3 standards - UMTS, WCDMA and CDMA2000 and provides speeds from $384 \mathrm{kbit} / \mathrm{s}$ to 2.4 $\mathrm{Mbit} / \mathrm{s}$ and enables new services such as video chat, radio and TV reception, and so on.

The fourth generation of mobile technologies 4G is a set of standards for broadband Internet access from mobile phones and tablets. Novelty is the voice transmission over the Internet through the VoIP protocol. The most serious contender among the currently developed standards is LTE (LongTerm Evolution). Another competitor is the Worldwide Interoperability for Microwave Access (WiMAX) technology already available from many broadcasters around the world, mostly wireless.

The new standard 5G will provide gigabit speeds exceeding the existing speeds. In addition, a minimum ping will be maintained for several milliseconds. The standard will be energy-efficient, which will allow small-device connectors to be built in, bringing users closer to "internet gadgets" and the concept of Internet of things. As a result of the implementation of the standard to the global network and the increased capacity of the networks, it will be possible to include virtually all possible equipment, including household appliances, such as running teapots and lamps, cars, traffic lights, and weather sensors (7).

\section{MOBILE APPLICATIONS}

Every mobile application (app) is software that is designed to be installed on a mobile device. Typically, these apps are small and have less features than those designed for computers and laptops.

\subsection{MOBILE APP STORES}

Each mobile app is created for specific OS and can be downloaded from a special location (app store), depending on the mobile OS. The main official app stores are:

- Android - Google Play;

- iOS - App Store;

- Windows 10 Mobile - Microsoft Store;

- BlackBerry 10 - BlackBerry World, Amazon Appstore
- Tizen - Tizen Store

- Sailfish OS - Jolla Store

- Ubuntu Touch - OpenStore

It could be surprisingly and interesting to most of non-professional users that besides of official distribution channels there is a huge number of their alternative mobile app stores that could be grouped by platform, manufacturer, location and mobile operator. They can offer different type of revenue share model, not the one (70/30) that is supported by the Google Play and App Store and pay for a certain number of downloads that will make the applications more popular. These new alternative app stores will play a major role in the distribution of mobile application and will change their marketing strategy.

Some of the alternative mobile channels are listed below (8):

- List of Android App Stores - Google Play, Amazon AppStore, GetJar, Aptoide, Opera Mobile Store, SlideMe,1Mobile;

- Top App Stores for iOS - App Store, Cydia, GetJar, Appland;

- Cross-platform App Stores - Amazon AppStore, GetJar, Opera Mobile Store, Appszoom, Appolicious, NexVa, Kongregate;

- Manufacturer-specific App Stores Samsung Apps, LG Smart World, Huawei;

- Top China App Stores - MyApp (Tencent), 360 Mobile Assistant, Xiaomi App Store, Baidu Mobile Assistant, Xiaomi Game Center, Huawei App Market.

Each year the number of developed and downloaded apps grows. Statista (9) reported that in 2017 consumers downloaded 178.1 billion mobile apps to their connected devices, for 2018 their number grown to 205.4 and the forecast for 2022 is that the downloaded apps will reach up to 258.2 billion.

The Figure 1 shows that for the first quarter of 2019 Google Play is the biggest mobile applications store with a collection of 2100 000 apps, followed by App Store with 1 800000 (10).

\subsection{MOBILE APPLICATIONS FEATURES}

Nowadays the number of existing mobile applications expands tremendously and almost every day developers upload new ones to the markets, but not every one of these apps has a long life of usage. 


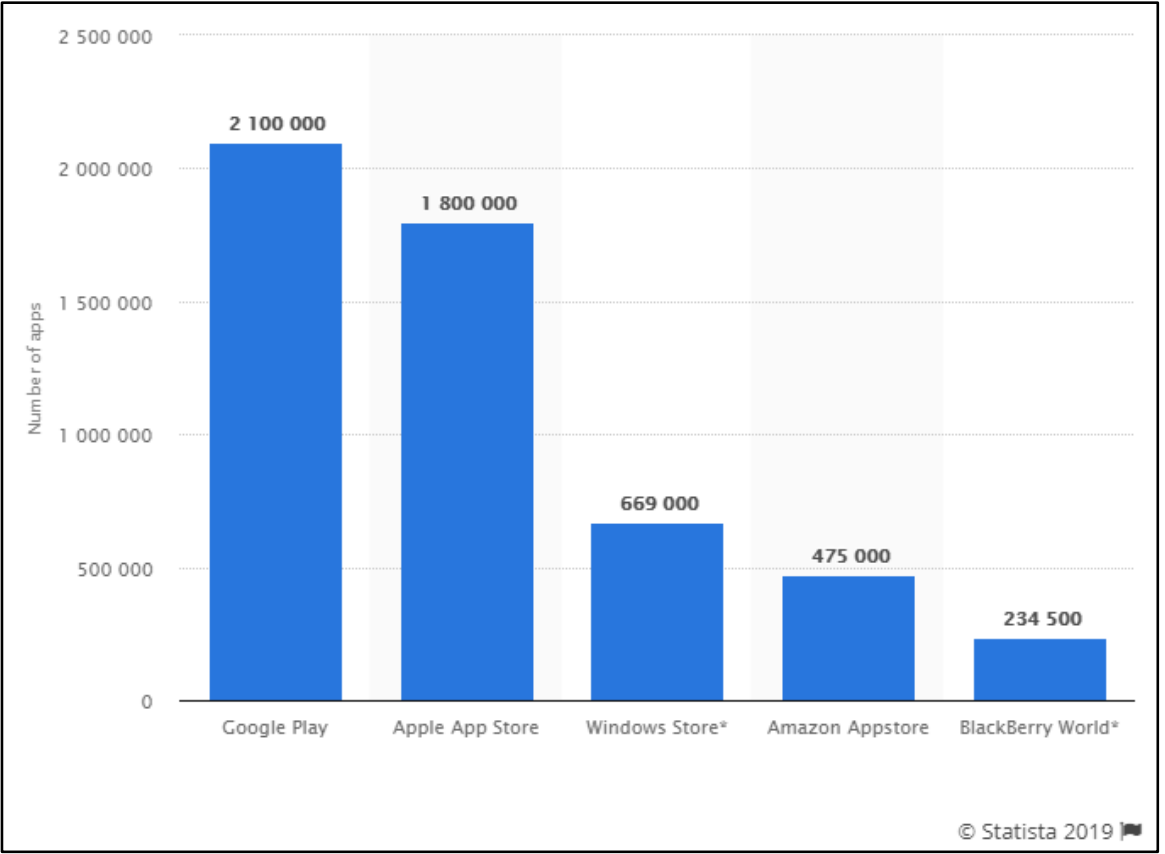

Figure 1. Number of apps available in leading app stores as of 1st quarter 2019

According to a survey (11), the main reasons why users delete mobile apps from their phones are: App wasn't used (32\%), App didn't fulfill needs (26\%), Lack of phone storage space $(25 \%)$. The large size of apps is related to their ability to be used in offline mode when there is no internet connection. This is an extremely important feature for an application because users are not limited and can use it anywhere. A great example of such application is Google Translate, which allows downloading different packages for the language that the user wants to translate.

There are many factors that make mobile applications successful $(12,13)$. Some of the most important features that a mobile application should possess are:

- High-quality product that combines good design and functionality. This means that the main purpose of a successful mobile app is to be able to solve a specific problem for users;

- Viral effect - embedded social media sharing features that provide free channels for advertisement;

- Versions for different mobile operating systems (Android, iOS or others). Reaching more platforms and devices will provide more popularity, users and product independence;

- Analysis options that track which features are most commonly used and allow timely optimization, debugging and troubleshooting;

- Free applications are preferred over their alternative paid ones and it allows to be used by a wider audience;

- A successful marketing plan that includes good mobile app promotion across app stores sites and social media;
- Security is an extremely important feature for any mobile application that includes both security data transfer over the network and protection from direct access to the mobile device itself;

- Individualization or personalization that includes features to create personalized content and meet the user's needs, depending on the way he uses the app.

\section{MOBILE APPLICATIONS FOR BUSINESS}

First of all, it is important to highlight the underlying reasons that show why business needs mobile applications (14). Some of these reasons are related to:

- Visibility of the business to customers at any time and place;

- Creating a direct marketing channel providing information and reminders, product brochures and customer service with just a few clicks;

- Added value for customers who are loyal to the business - digitalizing the program for collecting points and rewards through developing a company mobile application will result in more downloads for the app;

- Building a brand for recognition - the mobile app can increase the consumers' awareness of your brand;

- Improving customer engagement - the ability to include features for quick and easy access to your business;

- Being innovators and progressive in thoughts and actions - although mobile applications for small businesses are rare, creating them is a way to distinguish from 
others and be different and keep pace with new technologies.

Undoubtedly, every business needs an application that is convenient and easy to use by the customers for all the things they do every day - communication, online shopping, booking hotels, tickets, mobile banking and etc. From another perspective, each company also needs a variety of mobile applications to manage its business from anywhere and anytime.

Typically, mobile apps are categorized according to the purpose of their use, such as Business, Communication, Education, Entertainment,
ANGELOVA N.

Finance, Food, Medical, Maps \& Navigation and many more.

Business applications can also be classified and grouped according to the objectives and functions of the business organization and the main tasks performed by the manager and the employees.

The main activities of each company are related to task managing, planning and organizing of events and meetings, communication with employees, partners and consumers.

The most popular apps in Business category in the two major app stores (Google Play and App Store) are presented in Table 2. (15, 16):

Table 2. List of popular and recommended mobile apps for business in Google Play and App Store

\begin{tabular}{|l|l|l|}
\hline Subcategory & Google Play & App Store \\
\hline Office suits & $\begin{array}{l}\text { OfficeSuite, Docs To Go } \\
\text { Office Suite, SmartOffice, Polaris } \\
\text { Office - Free Docs, Sheets, Slides + } \\
\text { PDF }\end{array}$ & $\begin{array}{l}\text { Documents (Office Docs), } \\
\text { OfficeSuite \& PDF editor }\end{array}$ \\
\hline Scanning tools & Clear Scan, Fast Scanner & $\begin{array}{l}\text { Genius Scan - PDF Scanner, } \\
\text { Scanner++ PDF Document Scan }\end{array}$ \\
\hline $\begin{array}{l}\text { Job search, hire staff, job } \\
\text { interviews }\end{array}$ & $\begin{array}{l}\text { Glassdoor - Job Search, Salaries \& } \\
\text { Company Reviews, JOB TODAY: } \\
\text { Find Jobs, Build a Career \& Hire } \\
\text { Staff, } \\
\text { HireVue for Candidates, JobSwipe TM } \\
\text { - Search Millions of Jobs }\end{array}$ & $\begin{array}{l}\text { Indeed Job Search, CareerBuilder Job } \\
\text { Search, Snag - Jobs Hiring Now, } \\
\text { Glassdoor - Jobs \& Salaries }\end{array}$ \\
\hline Employee Scheduling & $\begin{array}{l}\text { When I Work Employee Scheduling, } \\
\text { 7shifts Employee Scheduling, } \\
\text { Humanity - Employee Scheduling, } \\
\text { Paylocity Mobile }\end{array}$ & $\begin{array}{l}\text { Workday, HoursTracker: Hours and } \\
\text { Pay, Crew Messaging and Scheduling }\end{array}$ \\
\hline Video conferencing tools & $\begin{array}{l}\text { Hangouts Meet, TrueConf Free 4K } \\
\text { Video Calls, GoToWebinar, } \\
\text { GoToMeeting - Video Conferencing } \\
\text { \& Online Meetings }\end{array}$ & $\begin{array}{l}\text { ZOOM Cloud Meetings, Cisco } \\
\text { Webex Meetings }\end{array}$ \\
\hline Planning, Task lists & $\begin{array}{l}\text { AWS Events, Teamup Calendar, } \\
\text { Tasks: Todo list, Task List, Reminder }\end{array}$ & $\begin{array}{l}\text { Trello - Organize anything!, Asana: } \\
\text { organize tasks \& work, HotSchedules }\end{array}$ \\
\hline $\begin{array}{l}\text { Automated expense } \\
\text { management, Invoices, } \\
\text { payments }\end{array}$ & $\begin{array}{l}\text { Invoice Maker: Estimate \& Invoice } \\
\text { App, SAP Concur, } \\
\text { Invoice 2go - Professional Invoices } \\
\text { and Estimates }\end{array}$ & $\begin{array}{l}\text { Expensify: Receipts \& Expenses, } \\
\text { QuickBooks 2go Invoice \& Estimate, } \\
\text { Point of Sale (POS) }\end{array}$ \\
\hline
\end{tabular}

In the Finance category, the main recommended applications are connected with money transfer and payments, mobile banking applications, investment applications.

Security is very important feature of all these applications due to operating with money and stocks so users should be aware and work carefully with them.

For Bulgarian customers there are some applications for operating bank institutions like Bulbank mobile, Raiffeisen ONLINE, CCBank Mobile App, DSK Smart, My Fibank, available both for Android and iOS smartphones and devices.

Some of the problems, reported by the users and reviewers of some of these apps are: annoying adds offering paid versions, long time for loading the app, not very easy and convenient interface and features, some of the apps are developed only for one of the mobile OS and some do not work appropriately for one of the OS, do not support language versions, do not meet the characteristics of the mobile devices. 
Table 3. List of popular and recommended mobile apps for finance in Google Play and App Store

\begin{tabular}{|l|l|l|}
\hline Subcategory & Google Play & App Store \\
\hline $\begin{array}{l}\text { Mobile Payment, Money } \\
\text { transfer }\end{array}$ & $\begin{array}{l}\text { TransferWise: send, receive \& spend } \\
\text { money globally, } \\
\text { TransferGo: Money Transfer, } \\
\text { PayPal Mobile Cash: Send and } \\
\text { Request Money Fast }\end{array}$ & $\begin{array}{l}\text { Venmo: Send \& Receive Money, } \\
\text { JPay, PayPal: Mobile Cash, } \\
\text { WesternUnion US Money Transfer }\end{array}$ \\
\hline $\begin{array}{l}\text { Budget, Bills \& Credit } \\
\text { Score, Savings }\end{array}$ & $\begin{array}{l}\text { PNC Virtual Wallet, ePayments: } \\
\text { wallet \& bank card, Monthly Budget } \\
\text { Planner \& Daily Expense Tracker, } \\
\text { Wallet, Monefy }\end{array}$ & $\begin{array}{l}\text { Mint: Personal Finance \& Money, } \\
\text { Twine: Easy Saving \& Investing, } \\
\text { Digit: Save Money Effortlessly, } \\
\text { Goodbudget Budget Planner, PNC } \\
\text { Virtual Wallet }\end{array}$ \\
\hline $\begin{array}{l}\text { Invest in Stocks, Crypto, } \\
\text { ETFs }\end{array}$ & $\begin{array}{l}\text { MetaTrader 4 Forex Trading, } \\
\text { Webull: Invest Smart, Trade Free - } \\
\text { Stocks, ETFs., Investing.com: } \\
\text { Stocks, Finance, Markets \& News, } \\
\text { MSN Money- Stock Quotes \& News }\end{array}$ & $\begin{array}{l}\text { Stash: Invest. Learn. Save., } \\
\text { E*TRADE: Invest. Trade. Save. }\end{array}$ \\
\hline Mobile banking & $\begin{array}{l}\text { Bank of the West Mobile, TCF Bank, } \\
\text { Santander Bank US }\end{array}$ & $\begin{array}{l}\text { Simple - Better Banking, TCF Bank, } \\
\text { Chase Mobile } \text { ( ) U.S. Bank, Citizens } \\
\text { Bank Mobile Banking }\end{array}$ \\
\hline
\end{tabular}

\section{SURVEY}

One of the goals of this article is to present the results of a survey exploring the usage of mobile applications.

The questionnaire is created by Google Forms (https://forms.gle/LRT7KPvAFBCxcQwK8 ) and contains 12 questions. It was mainly disseminated via social media and the main target groups are students trained in some of the specialties of Trakia University (Faculty of Economics and Faculty of Agriculture).

The survey includes 51 respondents and the results shows that they were primary female $60 \%$, while male represent about $40 \%$. Most of them are students (full - time and part-time) so it is not unusual that $35.3 \%$ are between $20-30$ years old, followed by the group of 30-40 years $(27.5 \%)$, and the smallest proportion are consumers between $60-70$ years $(3.9 \%)$.

All respondents have a smartphone (98\%), and $2 \%$ have both devices - a smartphone and a tablet, with the most used mobile operating system Android (88.2\%) and those with iOS represent $11.8 \%$.

This is an expected result, which also coincides with the statistics presented in Table 1 that in Bulgaria devices with Android OS has the largest share.

Concerning the number of applications installed on the users' smartphones, $31 \%$ of them pointed more than 12 applications and $11.8 \%$ are those with between 4 and 6 applications. The survey shows that most of the respondents $(68 \%)$ searched and found the right application from the relevant platforms Google Play and App Store, 15,7\% were informed by friends, $11,8 \%$ relay on user's posts and reviews in social media sites and forums.

Based on the survey, it can be concluded that a large proportion of consumers use their mobile devices (smartphones and tablets) primarily for communication, including phone calls, social media, messaging, and entertainment - games, music, movies.

This statement is also confirmed by the fact that users are constantly using mobile social networking applications, messaging and e-mail services, and rarely or never take advantage of training and educational applications. Some of the examples of the most popular apps among respondents are Facebook, Instagram, Messenger, Viber, YouTube, Zedge.

The major mobile business applications that are mentioned are mainly related to mobile banking and it seems that business apps appear to be associated mainly with mobile banking. There are no examples of applications for accounting, finance, and human resources management, which could be a result by the fact that most of the respondents are students and a very small part run their own businesses. Concerning which features are essential for the mobile applications, users prefer the app to be free, to provide data security, application 


\section{ANGELOVA N.}

stability, be comfortable and easy to use, do not include ads that are annoying to users, and also the app to have an available version for different mobile OS.

\section{CONCLUSIONS}

Mobile devices are an integral part of our lives and it seems like everything we possess is inside them behind the screen. It has no longer been the only mean for connecting and talking with people who are far away from us. It is our personal assistant who wakes us up in the morning, reminds us of important meetings, captures moments with our loved ones and beautiful pictures, controls the appliances in our home, manages finances and business, finds everything we care about and helps us present it in appropriate form.

The question is whether we are able to take advantage of all of its capabilities through the various mobile apps that appear every day. What are the main features of these apps that attract users and whether they need a campaign to promote and advertise them?

Many mobile applications have also a desktop or cloud based versions that make them extremely convenient with the ability of synchronizing data when permanent internet access is provided from anywhere and at any time. Many of them are easy and convenient to use, and visualization and navigation are tailored to the capabilities of mobile devices and their displays.

Essential for the development of mobile applications will be the adoption of the new generation mobile communications, including the $5 \mathrm{G}$ standard that will provide a much faster connection and many more new opportunities for consumers. One of the factors that determine the direction and the future in the development of mobile applications and their impact on business models of different companies is the growing number of connected smart devices, part of the concept of the Internet of Things that can be controlled through mobile applications on smart phones.

\section{REFERENCES}

1. TigerMobiles.com, Evolution of the mobile phone,

https://www.tigermobiles.com/evolution/\#zer oPhone, last access 24.07.2019

2. IGI Global, What is Mobile Technology, https://www.igi-

global.com/dictionary/mobile-strategy-

business-solution/18956 , last access 24.07.2019
3. Viswanathan P., What Is a Mobile Operating System?, 2019 , https://www.lifewire.com/what-is-a-mobileoperating-system-2373340, last access 24.07.2019

4. Statcounter, Mobile Operating System Market Share United States Of America, 2019, http://gs.statcounter.com/os-marketshare/mobile/united-states-ofamerica/\#yearly-2019-2019-bar

5. Prakash A. Open Source Mobile OS Alternatives To Android, 2019, https://itsfoss.com/open-source-alternativesandroid/, last access 24.07.2019

6. Javatpoint, Introduction to Mobile Communication, https://www.javatpoint.com/mobilecommunication-introduction, last access 24.07.2019

7. Mobile communications, https://mobiledevices.webnode.com/istoriya-na-mobilnitetelefoni/mobilni-komunikatsii/, last access 24.07.2019

8. Dogtiev A., App Stores List (2018), 2019, https://www.businessofapps.com/guide/appstores-list/, last access 24.07.2019

9. Statista, Annual number of global mobile app downloads 2017-2022, https://www.statista.com/statistics/271644/wo rldwide-free-and-paid-mobile-app-storedownloads/

10. Statista, Number of apps available in leading app stores 2019, (https://www.statista.com/statistics/276623/nu mber-of-apps-available-in-leading-app-stores/

11.Panko R., Mobile App Usage Statistics 2018, 2018, https://themanifest.com/appdevelopment/mobile-app-usage-statistics2018, last access 24.07.2019

12. Whiz, Kakvo pravi edno mobilno prilozhenie uspeshno, https://www.whiz.bg/blog/kakvopravi-edno-mobilno-prilozhenieuspeshno.html, last access 24.07.2019

13. Ittechsols,Some Essential Characteristics of Mobile Applications, 2012, https://ittechsols.wordpress.com/2012/12/18/s ome-essential-characteristics-of-mobileapplications/

14. Haselmayr M., 7 Reasons Why Your Business Needs a Mobile App, https://www.allbusiness.com/7-reasonsbusiness-needs-mobile-app-19179-1.html, last access 24.07.2019

15. App Store, https://apps.apple.com/us/genre/iosbusiness/id6000, last access 20.07.2019

16. Google Play,https://play.google.com/store/apps/categ ory/BUSINESS?hl=en_US, last access 20.07.2019 